\title{
Fine Structure of the Neuroganglia in the Central Nervous System of the Harvestman Leiobunum japonicum (Arachnida: Opiliones)
}

\author{
Yong-Ki Park, Hye-Yoon Gu, Hyun-Jung Kwon, Hoon Kim, Myung-Jin Moon*
}

Department of Biological Sciences, College of Natural Science, Dankook University, Cheonan 31116, Korea

*Correspondence to:

Moon MJ,

(iD) http://orcid.org/0000-0001-9628-4818

Tel: +82-41-550-3445

Fax: +82-41-550-3409

E-mail: moonmj@dankook.ac.kr

Received January 28, 2018

Revised February 21, 2018

Accepted March 3, 2018
The characteristic features of the arachnid central nervous system (CNS) are related to its body segmentation, and the body in the Opiliones appears to be a single oval structure because of its broad connection between two tagmata (prosoma and opisthosoma). Nevertheless, structural organization of the ganglionic neurons and nerves in the harvestman Leiobunum japonicum is quite similar to the CNS in most other arachnids. This paper describes the fine structural details of the main groups of neuropiles in the CNS ganglia revealed by the transmission electron microscopy. In particular, electron-microscopic features of neural clusters in the main neuroganglia of the CNS (supraesophageal ganglion, protocerebral ganglion, optic lobes, central body, and subesophageal ganglion) could provide indications for the nervous pathways associated with nerve terminations and plexuses. The CNS of this harvestman consists of a supraesophageal ganglion (brain) and a subesophageal mass, and there are no ganglia in the abdomen. Cell bodies of neuroganglia are found in the periphery, but central parts of the ganglia are mostly fibrous in all ganglia. Neuroglial cells occupy the spaces left by nerve cells. Since the nerve cells in the ganglia are typical composed of monopolar neurons, axons and dendrites of neurons are distributed along the same direction.

Key Words: Fine structure, Central nervous system, Neuroganglia, Harvestman, Leiobunum japonicum

\section{INTRODUCTION}

Harvestmen are very old arachnids. Well-preserved fossils have been found from the Devonian period, 410 million year ago. Fossil records show that the basic structure of the harvestmen has not changed much since then a phenomenon called stasis (Machado et al., 2007). Although phylogenetic position is disputed, they are probably closely related to the mites or scorpions, pseudoscorpions and solifuges (Shultz, 1998; Weygoldt, 1985). Traditionally, the order Opiliones is regarded as a close relative of mites (Weygoldt, 1985), mainly because of morphological similarities in external body structure. In addition, recent research places harvestmen near Scorpiones, Pseudoscorpiones, and Solifugae, a view based primarily on similarities of the appendages and mouthparts (Giribet \& Kury, 2007; Shultz \& Pinto-da-Rocha, 2007).

The Opiliones have exceptionally long legs relative to their body size and have no silk glands and venom glands, therefore do not build webs and pose no danger to humans. The unique difference between harvestmen and spiders is that in harvestmen, the connection between the prosoma (cephalothorax) and opistosoma (abdomen) is broad, so that the body appears to be a single oval shape (Machado et al., 2007). Studies have shown that structure of the arachnid central nervous system (CNS) and their neural connections are related to their body segments (Ruppert et al., 2004) and to the degree of development of segmental appendages and sense organs (Goodman et al., 1981; Weygoldt, 1985).

(a) This is an open-access article distributed under the terms of the Creative Commons Attribution Non-Commercial License (http://creativecommons.org/licenses/by-nc/4.0) which permits unrestricted noncommercial use, distribution, and reproduction in any medium, provided the original work is properly cited.

Copyrights @ 2018 by Korean Society of Microscopy 
Following fine work of the arachnid CNS (Babu, 1975), several other workers (Babu, 1985; Babu \& Barth, 1984; Doeffinger et al., 2010; Hill, 2006; Hwang \& Moon, 2003; Park et al., 2013; Weltzien \& Barth, 1991; Weygoldt, 1985) have reported structural organization of the CNS of arthropod animals. However, most of our anatomical and histological understandings of Opilione CNS comes from only a few authors (Shultz \& Pinto-da-Rocha, 2007). In particular, the major features of the opilione CNS have been concentrated in the neurosecretory system of the protocerebral part which is connected to a neurohemal organ (Juberthie, 1983; Juberthie \& Juberthie-Jupeau, 1974; Meyer et al., 1998), and several other parts of the brain (Breidbach \& Wegerhoff, 1993; Juberthie, 1983; Juberthie \& Juberthie-Jupeau, 1974; Meyer et al., 1998; Park \& Moon, 2016).

Although opiliones are the third-largest group of arachnids (Giribet \& Kury, 2007) and over 6,500 species have been discovered worldwide (Kury, 2015), harvestmen are a scientifically neglected group. Researches on these arachnids is still an unexplored field comparing to other arthropod animals. To begin filling this gap, here we have examined fine structure of CNS ganglia in the harvestman Leiobunum japonicum with light and electron microscopy.

\section{MATERIALS AND METHODS}

The harvestman L. japonicum Müller (Arachnida: Opiliones: Sclerosomatidae) were collected in a local area near the Cheonan campus of Dankook University, Cheonan-si, Chungcheongnam-do, Korea. All specimens were anesthetized with $\mathrm{CO}_{2}$ and dissected under a dissecting light microscope in a drop of $0.1 \mathrm{M}$ phosphate-buffered saline solution ( $\mathrm{pH} 7.4$ ). Both of brain and other central nervous tissues for histologic preparation were fixed in alcoholic Bouin's solution which consists of picric acid, glacial acetic acid, and formaldehyde. Following fixation, samples were dehydrated in ascending concentrations of ethanol $4^{\circ} \mathrm{C}$ from $30 \%$ to $100 \%$ for 30 minutes at each concentration with one repeat at $100 \%$. After dehydration, the specimens were transferred to xylene for clearing, and they were embedded with Paraplast embedding medium (Fisher Scientific Co., USA) immediately. The sections were cut with a thickness of approximately $5 \mu \mathrm{m}$ using a rotary microtome, Leica RM2135 (Leica Microsystems AG, Germany) and they were stained with H\&E solutions. Most specimens were photographed using a microscope, Nikon eclipse 80i (Nikon Instruments Inc., USA).

Specimens for a transmission electron microscopic examination were cut into pieces with a sharp razor blade and fixed in Karnovsky's solution buffered with $0.1 \mathrm{M}$ phosphate buffer solution (PBS; pH 7.4). Postfixation was performed with $1 \%$ osmium tetroxide in $0.1 \mathrm{M}$ phosphate buffer and washed several times in the same buffer following fixation. The specimens were then dehydrated in ascending concentrations of ethanol and embedded in Poly/Bed 812 Araldite Medium (Polysciences Inc., USA) via propylene oxide.

Semithin sections with approximately $200 \mathrm{~nm}$ were obtained with Leica Richert Ultracut R ultramicrotome (Leica Microsystems) using a glass knife. For general orientation of the CNS, these sections were stained with toluidine blue dissolved in $1 \%$ borax. Ultrathin sections $(70 \mathrm{~nm})$ for transmission electron microscopic observation were obtained using an Ultra $45^{\circ}$ diamond knife (Diatome, USA), and were double stained with uranyl acetate, followed by lead citrate. After these treatments, the sections were examined with a JEM 2010 transmission electron microscope (JEOL, Japan) which provided by Daedeok Headquarters of the Korea Basic Science Institute (KBSI).

\section{RESULTS}

\section{Supraesophageal Ganglion}

The CNS in the harvestmen L. japonicum is consisted of a large cluster of nervous tissues with paired appendicular nerves (Fig. 1). The esophagus passes through the neural cluster and divides it into the upper supraesophageal ganglion

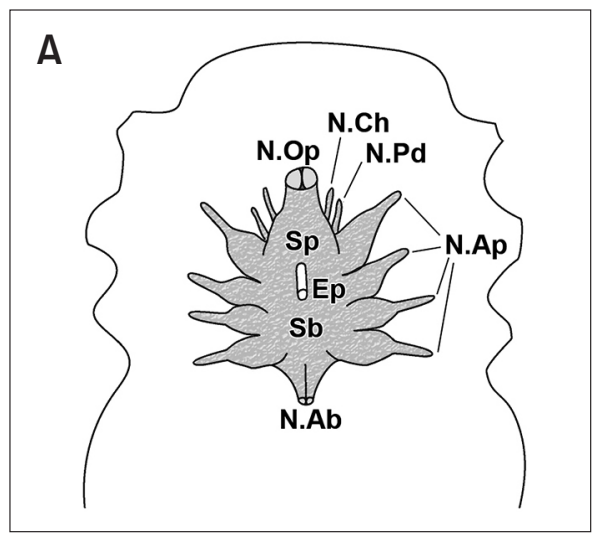

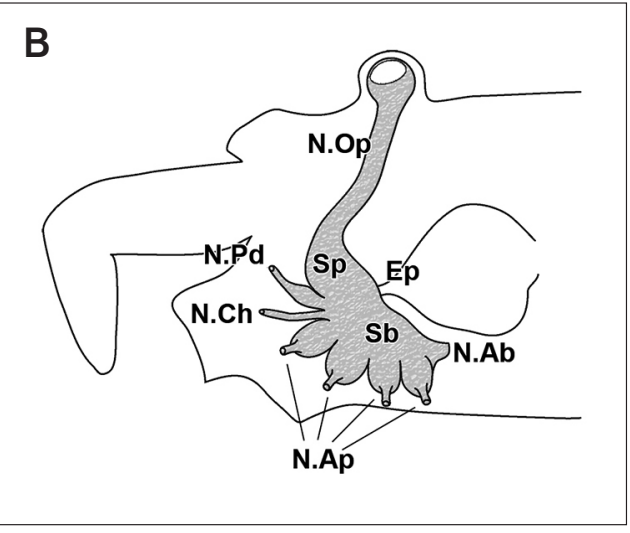

Fig. 1. Diagrams of the harvestman Leiobunum japonicum. (A) Frontal view. (B) Sagittal view. N.Op, optic nerve; N.Ch, cheliceral nerve; N.Pd, nerve of the pedipalp; Sp, supraesophageal ganglion; Ep, esophagus; Sb, subesophageal ganglion; N.Ap, nerve of the appendages; $\mathrm{N} . \mathrm{Ab}$, abdominal nerve. 

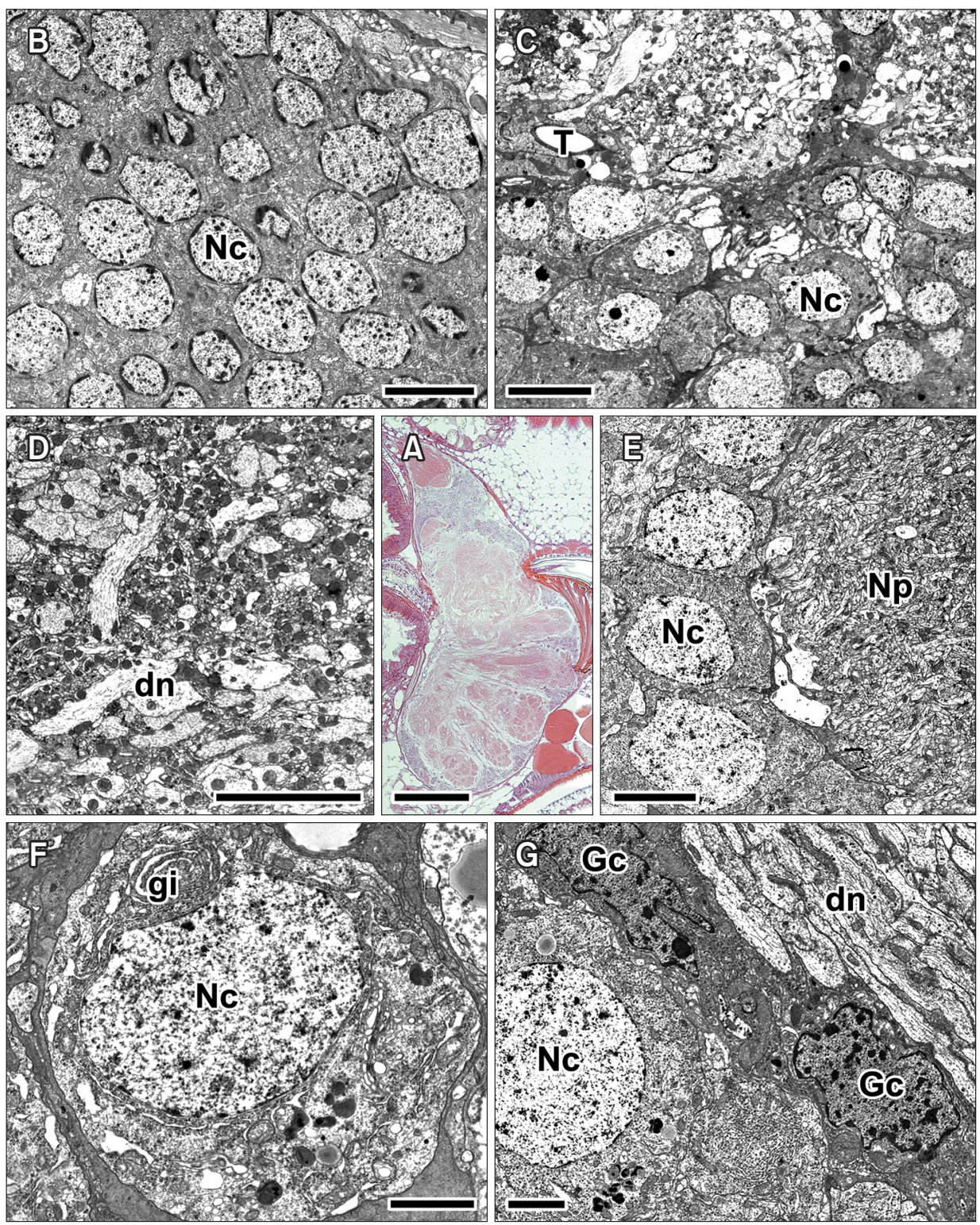

Fig. 2. The supraesophageal ganglion in the harvestman Leiobunum japonicum. (A) Photo micrograph of the supraesophageal ganglion. (B) The nerve mass consists of compact array of neuronal cells (Nc). (C) Cell bodies of the neurons are found mostly on the surface of the supraesophageal ganglion. $\mathrm{T}$, tracheole. (D) Central fibrous mass consists of processes of axons and dendrites (dn). (E) Cell bodies of the upper part of supraesophageal ganglion give off fine parallel bundles of neuronal processes (Np). (F) Each cell has a large nucleus and poorly stained cytoplasm with rough endoplasmic reticulum and Golgi complex (gi). (G) Neuroglial cells (Gc) occupy the spaces left by nerve cells. Scale bars $=500 \mu \mathrm{m}$ (A), $10 \mu \mathrm{m}$ (C and D), 5 $\mu \mathrm{m}$ (B and $\mathrm{E}), 2 \mu \mathrm{m}$ (F and $\mathrm{G}$ ). and the lower subesophageal ganglion based on the location of esophagus (Fig. 2A). The upper part of the esophagus consists of two main neural clusters, the protocerebral ganglion and the cheliceral ganglion. The nerve mass consists of compact array of cells surrounded externally by a thin layer of neural lamella (Fig. 2B). Cell bodies of the neurons are found mostly on the surface of the supraesophageal ganglion, and many axons penetrate the CNS (Fig. 2C).

Central fibrous mass of the subesophageal mass has no nerve cell body. It consists of processes of neurons and terminal arborizations of peripheral sensory neurons. This fibrous mass is highly organized in both longitudinal and transverse tracts with no synaptic contact (Fig. 2D). However, the upper part of supraesophageal ganglion has a numerous cell bodies. These cells give off fine parallel bundles of axon (Fig. 2E).
Each cell has a large nucleus and poorly stained cytoplasm after double staining with uranyl acetate and lead citrate (Fig. 2F). Neuroglial cells occupy the spaces left by nerve cells. The nuclei of neuroglial cells exhibits prominent nucleolus with large clumps of chromatin. The process of neuroglial cells is continuous around the surface of neurons, so that the nerve cells are ensheathed by neuroglial cells (Fig. 2G).

\section{Protocerebral Ganglion}

In protocerebrum, $L$. japonicum has four main groups of neuropiles; opic lobes, superior bilateral neuropil (central body), lateral neuropiles (corpora pedunculata, mushroom bodies), and inferior bilateral neuropil (Fig. 3A). The cells of the supraesophageal ganglion are arranged in the periphery, whereas the central part of the ganglia is fibrous. In particular, 

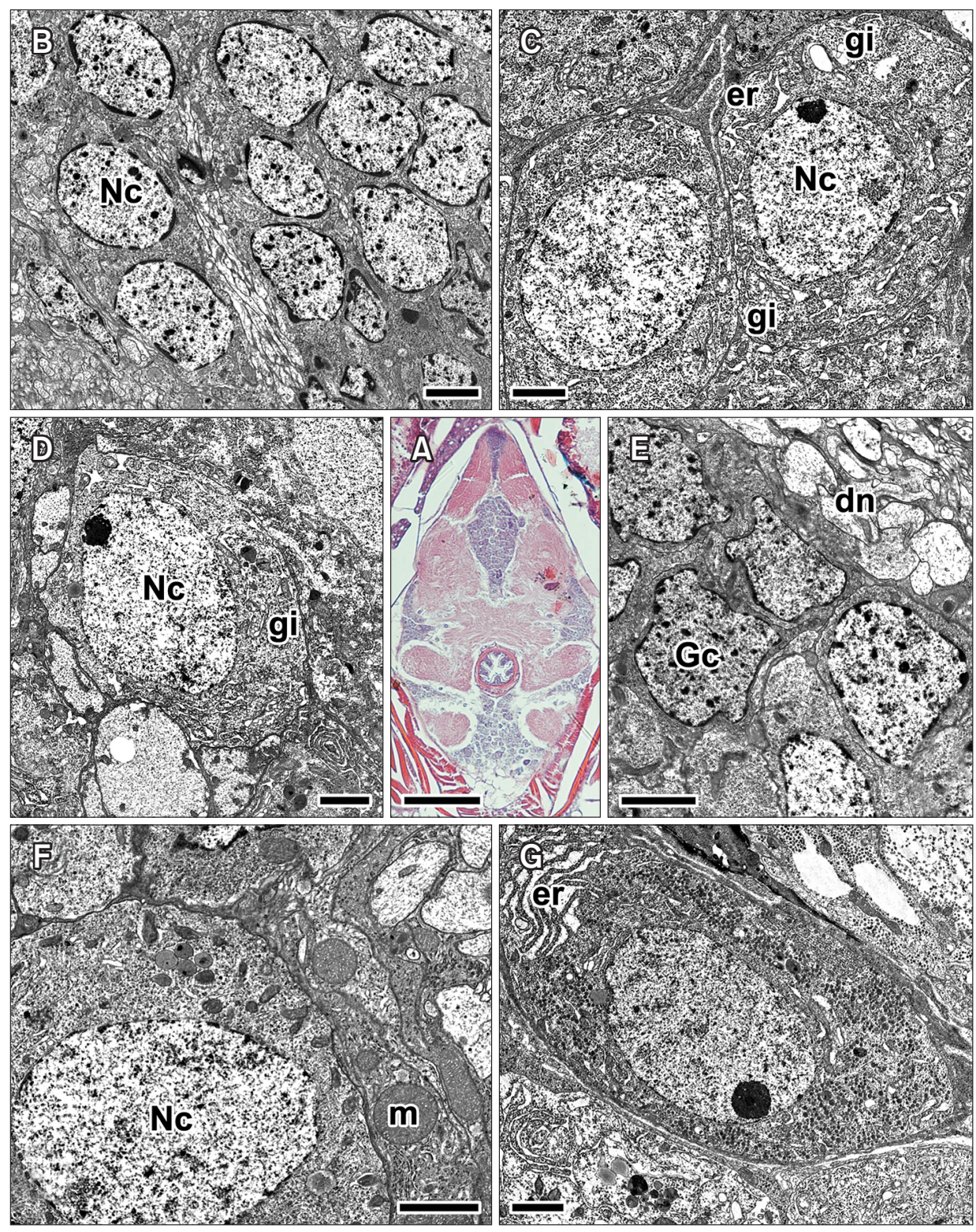

Fig. 3. The protocerebral ganglion in the harvestman Leiobunum japonicum. (A) Photo micrograph of the protocerebral ganglion. (B) The neuronal cells (Nc) of the supraesophageal ganglion are arranged in the periphery, whereas the central part of the ganglia is fibrous. (C) Near the nucleus, rough endoplasmic reticulum (er), free ribosomes, mitochondria, and prominent Golgi apparatuses (gi) are distributed. (D) Neuronal cells have a round and euchromatid nucleus and have an electron-lucent cytoplasm. (E) The processes of neuroglial cells (Gc) form a thin sheath around nerve cells. dn, dendrites. (F) The neuroglial cell involves large size mitochondria $(\mathrm{m})$ than that of neuronal cells. (G) Cell body of the neurosecretory cell contains a variable number of membrane-bound dense vesicles. Scale bars $=500 \mu \mathrm{m}(\mathrm{A}), 2 \mu \mathrm{m}$ (BG). dorsal part of the protocerbrum has a significantly condensed cell body compared to other parts of the CNS (Fig. 3B). The main types of neuronal cells have round and euchromatid nuclei, and have an electron-lucent cytoplasm. The nucleus of this neuronal cells is spherical or ovoid, and is relatively large compared to the size of the perikaryon (Fig. 3C).

Near the nucleus, cisternae of the rough endoplasmic reticulum ( $\mathrm{rER}$ ), free ribosomes and mitochondria are distributed. The prominent Golgi apparatuses are located very close to vesicles (Fig. 3D). The processes of neuroglial cells form a thin sheath consisting of several overlapping layers around nerve cells (Fig. 3E). The process penetrating neurons involves mitochondria and vesicles. The mitochondria are frequently larger than that of neuronal cells (Fig. 3F). Cell bodies of some type of nerve cell containing a variable number of membrane-bound dense vesicles showing the major neurosecretory products or enzymes involved in its synthesis (Fig. 3G).

\section{Optic Lobes}

The only nerve that arises in the protocerebrum of $L$. japonicum is the optic nerve connected to a pair of oceli. This optic nerve consists of two masses of optic neuropiles that originate in the dorsal part of the protocerebrum (Fig. $4 \mathrm{~A})$. In particular, the optic lobe in the anterior region of the protocerebrum is composed of several distinct neuropile masses, each mass surrounded by numerous neuronal cells (Fig. 4B). The neuropiles of the optic nerve are very thick and 

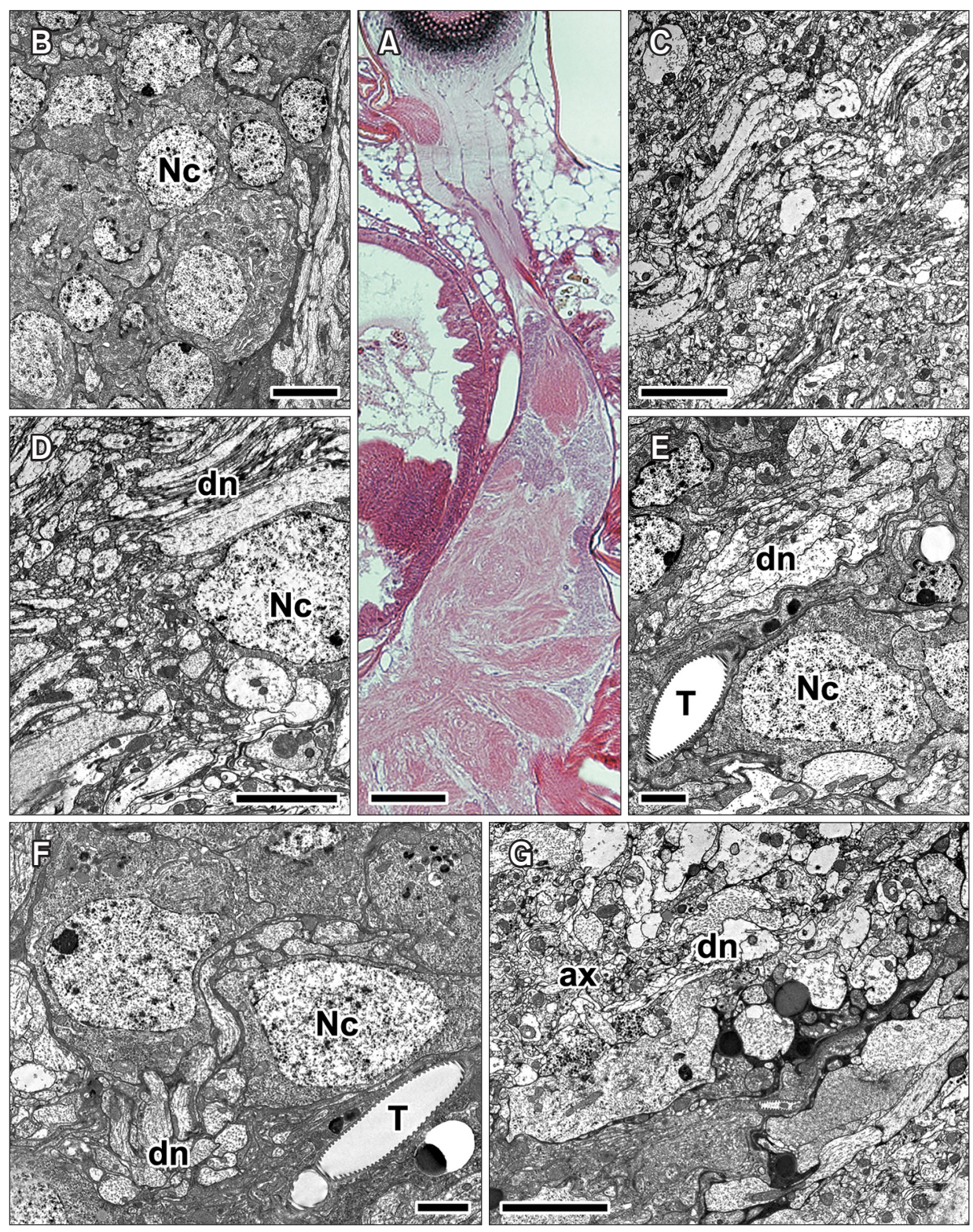

Fig. 4. The optic lobes in the harvestman Leiobunum japonicum. (A) Photo micrograph of the optic lobes connected to a pair of oceli. (B) The optic lobe in the anterior protocerebrum is composed of several distinct neuropile masses. Nc, neuronal cell. (C) Neuropiles of the optic nerve are consisted of the process of neurons and terminal arborizations. (D) Cell bodes, axons, and dendrites $(\mathrm{dn})$ are distributed along the same direction. (E) Dendrites contain rough endoplasmic reticulum, free ribosomes and Golgi complex. T, tracheole. (F) Near the neuronal cells (Nc) of the optic lobes a extensive processes of dendrites and tracheoles are seen. (G) Microtubules and neurofilaments are regularly aligned along the axis of the dendrites. ax, axons. Scale bars $=500 \mu \mathrm{m}$ (A), $5 \mu \mathrm{m}$ (B, C, and G), $2 \mu \mathrm{m}$ (D-F). abundant. It consists of the process of neurons and terminal arborizations of peripheral sensory neurons (Fig. 4C). Cell bodes, axons, and dendrites of neurons are distributed along the same direction in each ganglion (Fig. 4D).

Proximal portions of the dendrite contain significant amount of rough surface endoplasmic reticula, free ribosomes and components of the Golgi complex (Fig. 4E). Ribosomal material is present primarily in the form of multiple stacks of rER, but free ribosomes also exist. The Golgi complex is prominent near the nucleus and is seen as a group of sacs and vesicles surrounded by flat, extended smooth walls of varying sizes (Fig. 4F). The dendrites is seen as a bead with irregular expansion and constriction. Microtubules and neurofilaments are regularly aligned along the axis of the dendrites, and the number of tubules and filaments depends on the diameter of the dendrites (Fig. 4G).

\section{Central Body (Superior Neuropil)}

The central body is a flat, crescent-shaped neuropile mass extending over the posterior part of the dorsal protocerebrum. It is enclosed by its own membrane compartmented by the supraesophageal ganglion (Fig. 5A). The central body is covered with many layers of cell bodies in the dorsal and posterior regions. The neuronal cells of the central body give off fine parallel bundles of axons arranged on the mushroom body (Fig. 5B). Cell body of a neuron is supported by complex neurofilaments that are assembled into larger neurofibrils. Fibers from all ganglia communicate with complex regions of 

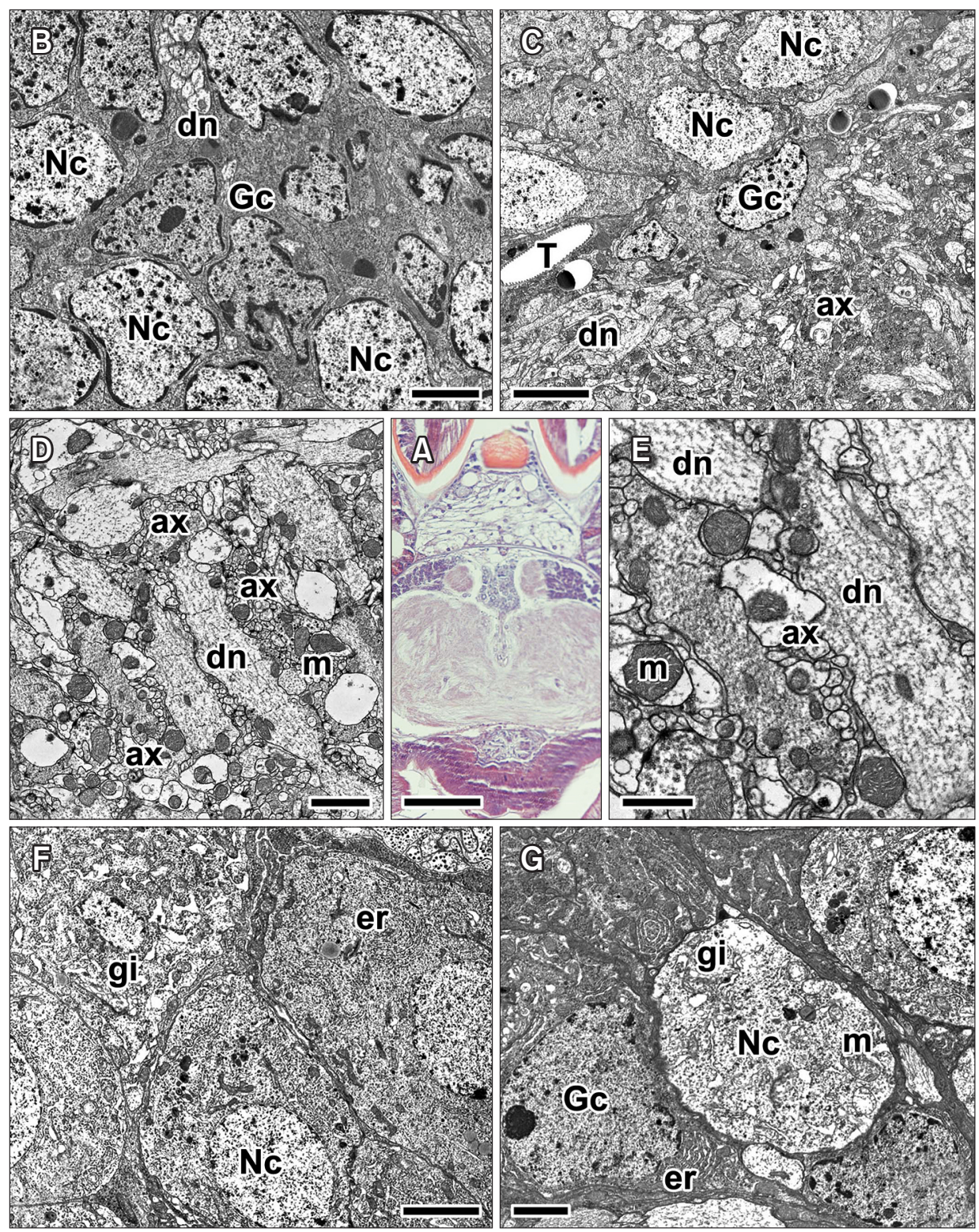

Fig. 5. The central body in the harvestman Leiobunum japonicum. (A) Photo micrograph of the central body which located at the posterior part of the dorsal protocerebrum. (B) The neuronal cells (Nc) of the central body give off fine bundles of dendrites (dn). GC, neuroglial cells. (C) Cell body of a neuron is supported by complex neurofilaments. T, tracheole; ax, axons. (D) Central fibrous masses consist of a extensive processes of neuronal axons (ax) and dendrites (dn). m, mitochondria. (E) Microtubules of the axon are uniformly oriented with highdensity parallel bundles. (F and G) Densecore vesicles are synthesized in the endoplasmic reticulum (er), packaged in a Golgi complex (gi). Scale bars $=500 \mu \mathrm{m}(\mathrm{A})$, $5 \mu \mathrm{m}(\mathrm{C}), 2 \mu \mathrm{m}$ (B, D, F, and G), $1 \mu \mathrm{m}$ (E). tracts and neuropiles (Fig. 5C).

Central fibrous masses do not have a nerve cell body, but instead consist of a extensive processes of neuronal axons and dendrites. The axons and dendrites include a linear arrays of uniformly arranged microtubules (Fig. 5D). The microtubules of the axon are uniformly oriented with high-density parallel bundles from the cell body to the distal end (Fig. 5E). Densecore vesicles in certain neurons of the central body are present in the perikaryon. This neurosecretory material is synthesized in the rER, packaged in a Golgi complex and transported in a large membrane-bound dense-core vesicle (Fig. 5F). These neuronal cells give off long and slender projection of axon bundles arranged on the mushroom body (Fig. 5G).

\section{Subesophageal Ganglion}

Nerves of the pedipalp, walking legs, and some for opisthosoma emerge from the lower part of esophagus. The subesophageal ganglion of the harvestman is composed of all the segmental ganglia in the posterior part. The subesophageal ganglionic mass consists of a single pair of pedipalpal ganglia, four pairs of appendage ganglia, and a fused mass of opisthosomal nerves (Fig. 6A). Cells in the subesophageal and abdominal ganglia are restricted to the ventral and lateral regions (Fig. 6B). Synaptic contact occurs mainly in the central fibrous core, but not in the cortex region. Therefore most cell bodies of neurons are found on the surface of the CNS (Fig. 6C).

Motor neurons have peripheral axons as well as relatively 

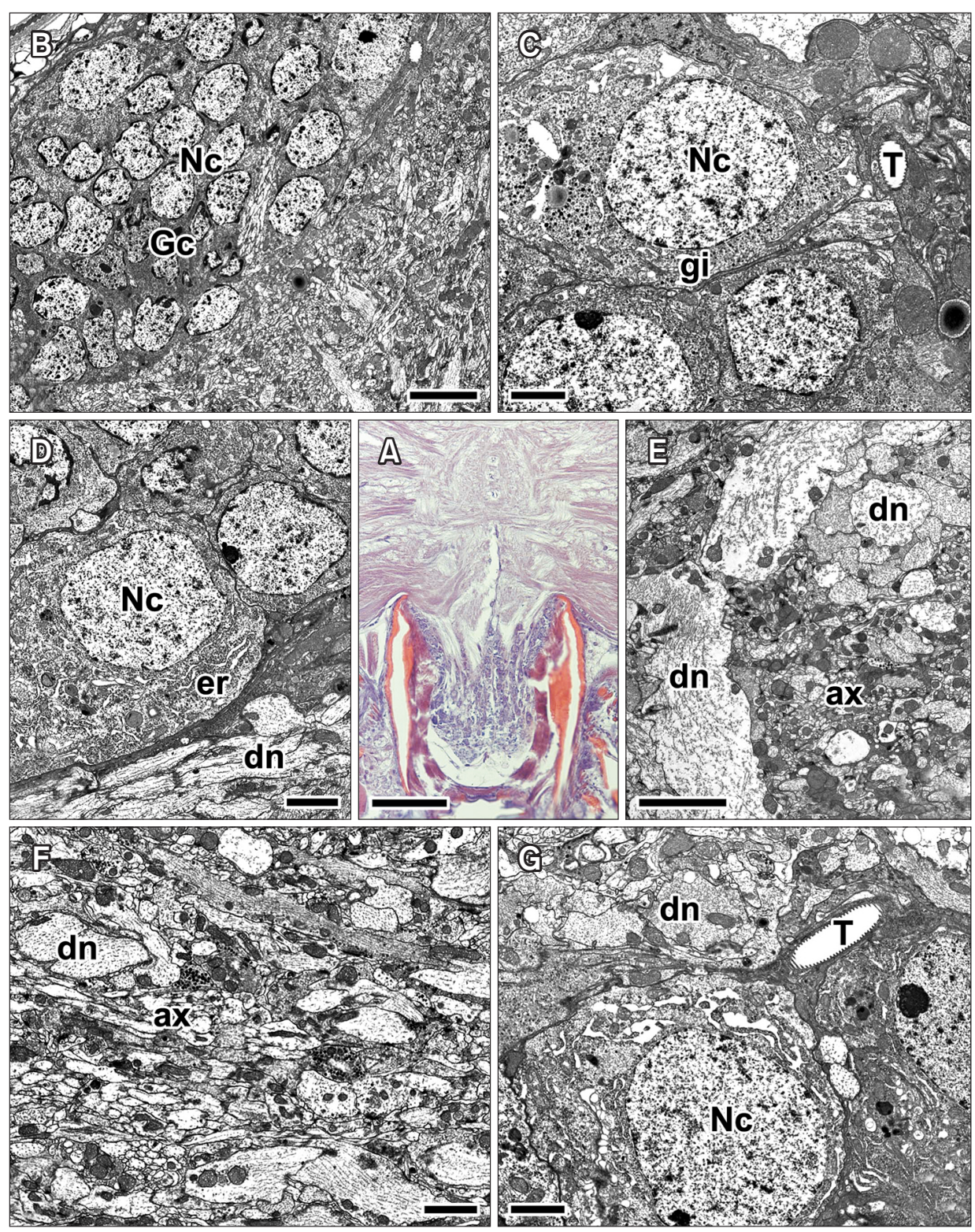

Fig. 6. The subesophageal ganglion in the harvestman Leiobunum japonicum. (A) Photo micrograph of the subesophageal ganglion. (B) Cells in the subesophageal ganglia are restricted to the ventral and lateral regions. Nc, neuronal cell; Gc, neuroglial cells. (C) Cell bodies of neuronal cells (Nc) are found on the surface area. gi, Golgi complex; T, tracheole. (D) Motor neurons have peripheral dendrites $(\mathrm{dn})$ as well as relatively large cell bodies. er, endoplasmic reticulum. (E) Neurofibrils are extended into both dendrites and axons (ax) by a complex network. (F) Central fibrous masses have processes of neurons and extensive peripheral axons. (G) Dense neuropiles are the synapsing sites between incoming sensory neurons and dendritic ramifications of motor neurons. Scale bars $=500 \mu \mathrm{m}$ (A), $5 \mu \mathrm{m}$ (B and E), $2 \mu \mathrm{m}$ (C, D, F, and G). large cell bodies. Cell bodes, axons and dendrites of the motor neurons are distributed along the same direction in each ganglion (Fig. 6D). Because the subesophageal nerve mass has many tracts of the sensory and motor neurons, the neurofibrils are extended into both dendrites and axons by a complex network (Fig. 6E). The central fibrous masses have no nerve cell bodies, instead they consisted of processes of neurons and extensive peripheral axons (Fig. 6F). Dense neuropiles connected with each ganglia are the synapsing sites between incoming sensory neurons and dendritic ramifications of associated motor neurons (Fig. 6G).

\section{DISCUSSION}

Previous works have clearly shown that the structure of arachnid CNS and their neural connections are related to the body segment (Goodman et al., 1981; Mittmann \& Scholtz, 2003; Strausfeld, 1998; Weygoldt, 1985). Since arachnids have appendages on the prosoma and they do not have antennae or opisthosomal appendages (Barth, 2002; Foelix, 2011), these characteristic features are reflected by the structure of the CNS, and general architecture of the CNS has its unique organization comparing to other arachnid groups.

The Opiliones are an order of arachnids known as harvestmen or daddy longlegs with exceptionally long legs relative to their body size (Shultz \& Pinto-da-Rocha, 2007). They are closely 
related to spiders, but their body does not have the distinct division between the cephalothorax and abdomen seen in the spiders (Ruppert et al., 2004). Anatomically, the two main body sections are fused into two tagmata - an anterior prosoma and posterior opisthosoma - and joined by a broad juncture, so that they appear to be one oval structure (Shultz \& Pinto-da-Rocha, 2007).

Despite this difference, the basic architecture of the CNS is quite similar to those found in most other arachnid groups (Mittmann \& Scholtz, 2003; Strausfeld, 1998). Therefore, all the ganglia of all segments behind the esophagus are fused into one mass so that the prosoma is largely filled with nervous tissue, and there are no ganglia in the abdomen (Foelix, 2011; Ruppert et al., 2004). Accordingly, the CNS in L. japonicum is also located in the frontal portion of the prosoma and is made up of a large neural mass which consist of the upper supraesophageal ganglion and the lower subesophageal ganglion (Park \& Moon, 2016). Since the Opiliones do not have antennae or abdominal appendages, the nervous system for controling the appendages are concentrated on the cephalothorax, and the absence of antennae implies the absence of a deutocerebrum as found in crustaceans and insects (Gullan \& Cranston, 2010; Mittmann \& Scholtz, 2003; Strausfeld et al., 2006).

The supraesophageal ganglion of all arthropods was through to include three components - protocerebrum, deutocerebrum, and tritocerebrum. Previous studies have also shown that the chelicerate animals only have two units in the supraesophageal ganglion due to loss of the first antenae and deutocerebrum (Babu, 1985; Weygoldt, 1985). However, developmental genetic research on spiders (Damen et al., 1998) and mites (Telford \& Thomas, 1998) revealed that the chelicerae and cheliceral ganglion are homologous to the first antennae and duetocerebrum of other arthropods, and that no segmental components are missing in the chelicerae CNS (Mittmann \& Scholtz, 2003).

The optic masses of arachnids are poorly developed compared to insects or crustaceans, and these are exists as small masses of neuropile without any particular specialization (Babu, 1985). Although the segmentation of the arachnid brain is still not clear, it is generally accepted by the researchers of this area (Strausfeld \& Barth, 1993; Strausfeld et al., 1993) that the important and complex neuropile masses in arachnids are located in the protocerebrum of the supraesophageal ganglion.

The optic lobes in the harvestman L. japonicum, the protocerebrum is associated with the eyes, and fewer types of neurons are present in association with optic neuropile compared to insects and crustaceans. Although the eyes and the optic centers varies widely among the arachnids, histologic structure in the phalangioid Rilaena triangularis clearly shows that the protocerebrum receives the optic nerves and is mainly involved in the reception and processing of visual information (Breidbach \& Wegerhoff, 1993).

The purpose of the present investigation was to determine the electron-microscopic features of neurons and neuroglial cells in the CNS ganglia, as part of a wider investigation into the nervous centers and pathways associated with nerve terminations and plexuses. The application of electron microscopic techniques to the study of invertebrate CNS has revealed that the shape and arrangement and their connections with the brain and other ganglia suggest that they are associated with complex behavioral activities (Babu, 1985). In spite of drastic differences in the appearance of harvestmen and other arachnid CNS ganglia, the nature of the nerve cells in the ganglion is of particular interest, not only because of their functional importance in the transmission of stimuli but also because of their possible association with the significant nerve fiber population in the ganglion (Chiarodo, 1968).

The activities of the euchromatin aid in cell survival. Discovering how distinct chromatin domains are assembled and propagated is critical for understanding normal states of cells (Taneja et al., 2017). Nucleus of most nerve cells in $L$. japonicum is large relative to the size of the perikaryon and is euchromatic. In addition, one or two prominent nucleoli are present within the nucleus of the neuronal cell, and their fine structure is also typical of that in other protein sysnthesizing cells. These results strengthen the premise that euchromatin is lightly packed in the form of DNA, RNA, and protein, and is usually under active transcription of DNA to mRNA products (Fortuny \& Polo, 2017; Taneja et al., 2017). Because euchromatin is rich in gene concentration, and substantial part of the genome is continually being transcribed in keeping with the active synthetic state of cell (Petralia et al., 2015), the nuclear chromatin is generally dispersed when seen with the electron microscope and the nucleus usually has a vesicular appearance when viewed with the light microscope.

As seen in EM, the ribosomal material is mainly in the form of multiple stacks of rER, free ribosomes and attached ribosomes. These rER with rosettes of free ribosomes are known as the Nissl substances of neuronal cells. The ultrastructure of these Nissl bodies suggests they are primarily concerned with the synthesis of proteins for intercellular use. Although the cytoplasm of all neurons is basophilic because of their rich content of RNA, not all neurons have distinct Nissl bodies (Peters et al., 1991). Such bodies can be seen particularly well in the large motor neurons and in large root ganglion cells, but the cytoplasm of smaller neurons merely show a diffuse, dust-like basophilia. They are involved in protein synthesis and their prominence can be explained by the fact that nerve cells are very metabolically active. It has been already known that the neurons need an enormous amount of energy, and the brain is one of the most metabolically 
active tissues in the body (Peters et al., 1991).

The Golgi complex is also prominent in all neurons; at the electron-microscopic level, it is commonly seen as several groups of flattened and dilated smooth-walled sacs and vesicles of variable size. They are located usually near the nucleus of the neuronal cells in L. japonicum but sometimes extending into the bases of the larger dendrites. The reason for this well-developed Golgi complex is incompletely understood; but by analogy with its appearance in other secretory cells, it probably is engaged in both the glycosylation of proteins (Lodish et al., 2003) and the packaging of secretory products within membrane-bound vesicles such as synaptic vesicles (Hand \& Oliver, 1981).

The neuropiles of the optic nerve and fibrous masses of central body in L. japonicum, axons and dendrites of neurons are distributed along the same direction in each ganglion. In particular, dendrites in the subesophageal ganglia are consisted of a multi-branched network capable of receiving inputs from thousands of other cells. Since dendritic processes of neurons are essentially expansions of cytoplasm containing most of the organelles found in the cell body (Peters et al., 1991), the dendrites contain numerous orderly arrays of microtubules and significant amount of rough endoplasmic reticula, free ribosomes and components of the Golgi complex. Axons also contain bundles of microtubules and neurofilaments and scattered mitochondria, however the axoplasm lacks rER and free ribosomes beyond the initial segments.

The cell bodies of some types of neuron in L. japonicum contain variable numbers of membrane-bound dense-core vesicles that represent their main neurosecretory product involved in its synthesis. In a small neuron of the CNS ganglia, many dense-core vesicles about 60 to $80 \mathrm{~nm}$ in diameter are present in the perikaryon as well as in the axons and their terminals. This neurosecretory material is typically seen in association with the organelles that aid in the synthesis of proteins. This ribosomes enable the rER to synthesize protein. These proteins can then be transported to the rER and the
Golgi complex for further synthesis and processing of the membrane-bound, dense-core vesicles.

\section{SUMMARY}

This study reveals fine structural characteristics of the neuroganglia in the CNS of the harvestman L. japonicum with aid of high resolution transmission electron microscopy. This opiliones have unique body structure comparing to other arachnids since their main body sections (prosoma and ophistosoma) are not separated. Therefore, the main neuroganglionic architecture of the CNS (supraesophageal ganglion, protocerebral ganglion, optic lobes, central body, and subesophageal ganglion) were closely examined to understand organization of ganglionic neurons and nerves. The cells of the ganglia are distributed in the periphery and give off fine parallel bundles of axon, whereas the central part of the ganglia is fibrous. Compact array of cell masses are surrounded externally by a thin layer of neural lamella, and central fibrous masses are highly organized in both longitudinal and transverse tracts. Axons contain bundles of microtubules and neurofilaments and scattered mitochondria. Dendrites also contain numerous orderly arrays of microtubules and rER, free ribosomes and Golgi complexes.

\section{CONFLICT OF INTEREST}

No potential conflict of interest relevant to this article was reported.

\section{ACKNOWLEDGMENTS}

This study was partially supported by Dankook ChemBio Specialization for the Creative Korea II (CKII) grant funded by the Ministry of Education, Science and Technology.

\section{REFERENCES}

Babu K S (1975) Postembryonic development of the central nervous system of the spider Argiope aurantia (Lucas). J. Morphol. 146, 325337.

Babu K S (1985) Patterns of arrangement and connectivity in the central nervous system of arachnids. In: Neurobiology of Arachnids, ed. Barth F G, pp. 3-19, (Springer-Verlag, New York).

Babu K S and Barth F G (1984) Neuroanatomy of the central nervous system of the wandering spider, Cupiennius salei (Arachnida: Araneidae). Zoomorphology 104, 344-359.

Barth F G (2002) A Spider's World, Senses and Behavior, pp. 1-394, (Springer-Verlag, New York).
Breidbach 0 and Wegerhoff R (1993) Neuroanatomy of the central nervous system of the harvestman, Rilaena triangularis (Herbst, 1799) (Arachnida: Opiliones) - principal organization, GABA-like and serotonin-immunohistochemistry. Zoologischer Anzeiger 230, 55-81.

Chiarodo A J (1968) The fine structure of neurons and nerve fibres in the thoracic ganglion of the blowfly, Sarcophaga bullata. J. Insect Physiol. 14, 1169-1172.

Damen W G M, Hausdorf M, Seyfarth E A, and Tautz D (1998) A conserved mode of head segmentation in arthropods revealed by the expression pattern of Hox genes in a spider. Proc. Natl. Acad. Sci. USA 95, 10665-10670. 
Doeffinger C, Hartenstein V, and Stollewerk A (2010) Compartmentalization of the precheliceral neuroectoderm in the spider Cupiennius salei: development of the arcuate body, optic ganglia, and mushroom body. J. Comp. Neurol. 518, 2612-2632.

Foelix R F (2011) Biology of Spiders, 3rd ed., pp. 1-432, (Oxford University Press, New York).

Fortuny A and Polo S E (2017) Genome and epigenome maintenance by keeping histone turnover in check. Mol. Cell 66, 3-4.

Giribet G and Kury A B (2007) Phylogeny and biogeography. In: Harvestmen: The Biology of Opiliones, eds. Pinto-da-Rocha R, Machado G, and Giribet G, pp. 55-58, (Harvard University Press, Cambridge).

Goodman C S, Bate C M and Spitwzel N C (1981) Embryonic development of identified neurons: origin and trasnformation of the $\mathrm{H}$ cell. $J$. Neurosci. 1, 94-102.

Gullan P J and Cranston P S (2010) The Insects: An Outline of Entomology, 4th ed., pp. 23-120, (Wiley-Blackwell, Oxford).

Hand A R and Oliver C (1981) The Golgi apparatus: protein transport and packaging in secretory cells. Method. Cell Biol. 23, 137-53.

Hill D E (2006) The structure of the central nervous system of jumping spiders of the genus Phidippus (Araneae: Salticidae). MS thesis (republication version), (Oregon State University, Corvallis).

Hwang H J and Moon M J (2003) Fine structural analysis of the central nervous system in the spider, Achaearanea tepidariorum (Theridiidae: Araneae). Kor. J. Entomol. 33, 119-126.

Juberthie C (1983) Neurosecretory systems and heurohemal organs of terrestrial chelicerata (Arachnida). In: Neurohemal Organs of Arthropods, ed. Gupta A P, pp. 149-203, (Charles C. Thomas, Springfield).

Juberthie C and Juberthie-Jupeau L (1974) Ultrastructure of neurohemal organs (paraganglionic plates) of Trogulus nepaeformis (Scopoli) (Opiliones, Trogulidae) and release of neurosecretory material. Cell Tiss. Res. 150, 67-78.

Kury A B (2015) Opiliones are no longer the same-on suprafamilial groups in harvestmen (Arthropoda: Arachnida). Zootaxa 3925, 301340.

Lodish H, Berk A, Matsudaira P, Kaiser C A, Krieger M, Scott M P, Zipursky L, and Darnell J (2003) Molecular Cell Biology, 6th ed., pp. 659-666, (W H Freeman \& Co., New York).

Machado G, Pinto-da-Rocha R, and Giribet G (2007) What are harvestmen? In: Harvestmen: the Biology of Opiliones, eds. Pinto-da-Rocha R, Machado G, and Giribet G, pp. 1-13, (Harvard University Press, Cambridge).

Meyer W, Schardinel J, and Schlesinger C (1998) Distribution of acetylcholinesterase in the central nervous system of harvestmen (Arachnida: Opilionida). Neurosci. Lett. 256, 97-100.

Mittmann B and Scholtz G (2003) Development of the nervous system in the "head" of Limulus polyphemus (Chelicerata, Xiphosura): morphological evidence for a correspondence between the segments of the chelicerae and of the (first) antennae of Mandibulata. Dev. Genes Evol. 213, 9-17.

Park Y K, Kim H J, Kim H, and Moon M J (2013) Fine structure of the CNS ganglia in the geometric spider Nephila clavata (Araneae: Nephilidae). Entomol. Res. 43, 330-343.

Park Y K and Moon M J (2016) Microstructural organization of the central nervous system in the harvestman Leiobunum japonicum (Arachnida: Opiliones). Entomol. Res. 46, 345-353.

Peters A, Palay S L, and Webster H D (1991) The Fine Structure of the Nervous System: Neurons and their Supporting Cells, 3rd ed., (Oxford University Press, New York).

Petralia R S, Wang Y X, Mattson M P, and Pamela J Y (2015) Structure, distribution, and function of neuronal/synaptic spinules and related invaginating projections. Neuromol. Med. 17, 211-240.

Ruppert E E, Fox R S, and Barnes R D (2004) Invertebrate Zoology, 7th ed., (Brooks/Cole-Thomson Learning, Belmont).

Shultz J W (1998) Phylogeny of Opiliones (Arachnida): an assessment of the "Cyphopalpatores" concept. J. Arachnol. 26, 257-272.

Shultz J W and Pinto-da-Rocha R (2007) Morphology and functional anatomy. In: Harvestmen: The Biology of Opiliones, eds. Pinto-daRocha R, Machado G, and Giribet G, pp. 55-58, (Harvard University Press, Cambridge).

Strausfeld N J (1998) Crustacean-insect relationships: the use of brain characters to derive phylogeny amongst segmented invertebrates. Brain Behav. Evolut. 52, 186-206.

Strausfeld N J and Barth F G (1993) Two visual system in one brain: neuropils serving the secondary eyes of the spider Cupiennius salei. J. Comp. Neurol. 328, 43-55.

Strausfeld N J, Strausfeld C M, Loesel R, Rowell D, and Stowe S (2006) Arthropod phylogeny: onychophoran brain organization suggests an archaic relationship with a chelicerate stem lineage. Proc. Biol. Sci. 273, 1857-1866.

Strausfeld N J, Weltzien P, and Barth F G (1993) Two visual system in one brain: neuropils serving the principal eyes of the spider Cupiennius salei. J. Comp. Neurol. 328, 63-72.

Taneja N, Zofall M, Balachandran V, Thillainadesan G, Sugiyama T, Wheeler D, Zhou M, and Grewal S I S (2017) SNF2 family protein Fft3 suppresses nucleosome turnover to promote epigenetic inheritance and proper replication. Mole. Cell 66, 50-62.

Telford M J and Thomas R H (1998) Expression of homeobox genes shows chelicerate arthropods retain their deutocerbral segment. Proc. Natl. Acad. Sci. 95, 10671-10675.

Weltzien P and Barth F G (1991) Volumetric measurements do not demonstrate that the spider brain "central body" has a special role in web building. J. Morphol. 208, 91-97.

Weygoldt P (1985) Ontogeny of the arachnid central nervous system. In: Neurobiology of Arachnids, ed. Barth F G, pp. 20-37, (Springer-Verlag, New York). 